\title{
Social Privacy in Networked Publics: Teens' Attitudes, Practices, and Strategies
}

\author{
danah boyd and Alice Marwick \\ Microsoft Research \\ dmb@microsoft.com and amarwick@microsoft.com
}

Waffles, 17, NC1: Every teenager wants privacy. Every single last one of them, whether they tell you or not, wants privacy. Just because an adult thinks they know the person doesn't mean they know the person. And just because teenagers use internet sites to connect to other people doesn't mean they don't care about their privacy. We don't tell everybody every single thing about our lives. We tell them general information - names, places, what we like to do - but that's general knowledge. That's not something you like to keep private-- "Oh, I play games. I better not tell anybody about that." I mean-- that's not something that we do. So to go ahead and say that teenagers don't like privacy is pretty ignorant and inconsiderate honestly, I believe, on the adult's part.

There's a widespread myth that American teenagers don't care about privacy. The logic is simple: Why else would teenagers share so much on Facebook and Twitter and YouTube? ${ }^{2}$ There is little doubt that many - but not all - American teens have embraced many popular social media services. ${ }^{3}$ And there is little doubt that those who have are posting photos, sharing links, updating status messages, and commenting on each other's posts. ${ }^{4}$ Yet, as Waffles explains above, participation in such networked publics does not imply that today's teens have rejected privacy as a value. All teens have a sense of privacy, although their definitions of privacy vary widely. Their practices in networked publics are shaped by their interpretation of the social situation, their attitudes towards privacy and publicity, and their ability to navigate the technological and social environment. As such, they develop intricate

\footnotetext{
${ }^{1}$ The names used in this article are pseudonyms. Some were chosen by the participants themselves; others were chosen by the authors to reflect similar gender and ethnic roots as are embedded in the participants' given names. All identifying information in teens' quotes has been altered to maintain confidentiality.

${ }^{2}$ A 2008 Harris Interactive/CTIA survey about teens' relationship to their mobile was publicized as indicating that kids don't care about privacy because only $41 \%$ indicated that they were concerned about privacy and security issues when using their mobile:

http://files.ctia.org/pdf/HI_TeenMobileStudy_ResearchReport.pdf In 2010, Chris Jay Hoofnagle, Jennifer King, Su Li, and Joseph Turow found that young people's attitudes about privacy parallel adults' attitudes, but their skills in managing privacy online are often lacking.

${ }^{3}$ As of September 2009, the Pew Internet and American Life Project found that 73\% of American teens ages 12-17 use a social network site; only $8 \%$ of teens in their sample used Twitter. See Lenhart et. al. 2010.

${ }^{4}$ Of teens who are on social network sites, Pew found that $86 \%$ comment on friends' posts. They also found that 38\% of teens ages 12-17 shared content online; 14\% keep a blog. See Lenhart et. al. 2010.
} 
Paper to be presented at Oxford Internet Institute's "A Decade in Internet Time: Symposium on the Dynamics of the Internet and Society" on September 22, 2011.

strategies to achieve privacy goals. Their practices demonstrate privacy as a social norm that is achieved through a wide array of social practices configured by structural conditions. How teens approach privacy challenges the ways in which privacy is currently conceptualized, discussed, and regulated.

This paper examines how teens understand privacy and what strategies they take in their efforts to achieve social privacy. We describe both teens' practices and the structural conditions in which they are embedded, highlighting the ways in which privacy, as it plays out in everyday life, is related more to agency and the ability to control a social situation than particular properties of information. Finally, we discuss the implications of teens' practices, revealing the importance of social norms as a regulatory force.

The data used in this paper come from ethnographic fieldwork collected across 20 different U.S. states from 2006-2010. In addition to both online and offline participant observation, we conducted 16390 -minute semi-structured interviews. ${ }^{5}$ We strategically worked to sample across gender, race, ethnicity, religion, age, socioeconomic background, political background, and school engagement level. All of the teens that we interviewed were in high school or had recently dropped out of high school. We used a judgment sample to elicit diverse perspectives rather than attempting to obtain a representative sample. Privacy was the central topic of 58 interviews conducted in North Carolina, Massachusetts, Tennessee, and Washington DC in 2010. While we draw from the experiences of all the teens we interviewed, the voices of informants from these regions are overrepresented in the discussion.

\section{What is Privacy?}

Privacy is a fraught concept, with no clear agreed-upon definition. Philosophers and legal scholars have worked diligently to conceptually locate privacy and offer a framework for considering how and when it has been violated. ${ }^{6}$ Yet, fundamentally, privacy is a social construct that reflects the values and norms of everyday people. How people conceptualize privacy and locate it in their life varies wildly,

\footnotetext{
5 This ethnographic project is an extension of the one described in danah boyd's 2008 Taken Out of Context: American Teen Sociality in Networked Publics. A detailed account of the methodological procedures is available there.

${ }^{6}$ The definitions of privacy are numerous. Helen Nissenbaum (2010) relates multiple definitions of privacy and groups them based on whether they are normative or descriptive; emphasize access vs. control; or emphasize promoting other values vs. protecting a private realm. These include definitions from Ruth Gavison ("a measure of the access others have to you through information, attention, and physical proximity") (68); Jeffrey Reiman ("the condition under which other people are deprived of access to either some information about you or some experience of you") $(1976,30)$; Westin's "the claim of individuals, groups, or institutions to determine for themselves when, how, and to what extent information about them is communicated to others (Westin 1967,7), and Anita Allen (who defines three types of privacy: physical privacy, informational privacy, and proprietary privacy, 71). See Nissenbaum 2010 for a full discussion.
} 
Paper to be presented at Oxford Internet Institute's "A Decade in Internet Time: Symposium on the Dynamics of the Internet and Society" on September 22, 2011.

highlighting that a universal notion of privacy remains enigmatic. ${ }^{7}$ When we asked teens to define privacy for us, their cacophonous responses reveal the diverse approaches that can be taken to understand privacy. ${ }^{8}$ While these discussions do not help to determine a precise definition of privacy, how teens attempt to explain privacy demonstrates its importance to them.

Both legally and philosophically, privacy has been conceptualized as a dichotomy in which people are entitled to greater privacy protections in the domestic sphere due to its intimate and personal nature. ${ }^{9}$ Although teens recognize the spatial dimension of privacy, this dichotomy does not reflect the realities of young people's lives. For example, Jabari (17, TN) argues that privacy is "having my own space and not necessarily not having people involved in my life, but having the opportunity to be alone or to use my space individually." Jared $(17, \mathrm{TN})$ also recognizes that privacy is usually understood in terms of space, but he believes that it is impossible to actually achieve physical privacy because everyone is always invading his space; he lives in a one-room apartment with his brother, his father, and his father's down-on-his-luck friend. Given few opportunities to experience physical privacy, he focuses instead on what he has control over: his thoughts. "The only privacy we've got left in our lives is what we don't say and what we don't do, and that's really what tells the most about people, is not just the thoughts but what do they not want people to know." In this way, Jared settles for privacy in his head because of his inability to control his physical environment.

When adults think about privacy or private places, they often imagine the home as a private space. Yet, many of the teens that we interviewed rejected this, highlighting the ways in which home is not private for them. For example, when danah asked 14-year-old Leigh from Iowa if home was private, she said "Not to me, but to our family... My mom comes and looks in my room and stuff." Heather, a 16-year-old from Iowa, went further. "Because there are a lot of things that my mom does that make me feel like it's not private. I can be taking a shower and she'll come in, go to the bathroom, and leave. She has no respect for my personal privacy. I can be sitting on the computer talking to a friend and she'll be reading over my shoulder and I don't want her to. That's not really private to me. Private is kind of like a place where I can kind of go and just be by myself and not have to worry about anyone doing anything." When danah asked Heather for an example of a private place, she listed Panera Bread, a restaurant where she works part-time. "My coworkers, they'll come and talk to me but I still have my alone time. I'm sitting there by myself. If I'm listening to my music and doing my homework it's just kind of alone time. I'm relaxed." The absence of

\footnotetext{
${ }^{7}$ Anthropologists have found wild variations in how different communities understand and prioritize privacy. John L. Locke's Eavesdropping: An Intimate History (2010) weaves together many of these different accounts.

8 Teens are not alone in having diverse views about what constitutes privacy. Diverse adult perspectives are well documented in Christena Nippert-Eng's Islands of Privacy (2010).

${ }^{9}$ Allen 1999; Nissenbaum 2010, 94; Strandburg 2011
} 
Paper to be presented at Oxford Internet Institute's "A Decade in Internet Time: Symposium on the Dynamics of the Internet and Society" on September 22, 2011.

parents is regularly a key factor for teens to feel as though they have privacy. For example, 17-year-old Sam from Iowa told danah that his private places are "In my car or at a friend's house or something. I'm definitely not worried about it because they are not my parents, so, I'm a little more open." When teens explain where they can seek privacy, they focus more on who is present than the particular configurations of the space.

Access is a key part of many definitions of privacy; for example, Ruth Gavison writes that "privacy is a limitation of others' access to an individual" and that "a loss of privacy occurs as others obtain information about an individual, pay attention to him, or gain access to him." 10 Boundaries to access also play an important role in how some teens understand privacy. For example, Jeromy $(14, \mathrm{DC})$ says that privacy is "when you're trying to keep something from the world or yourself or people that you don't like." In listing off different examples of who shouldn't have access to certain information, Jeromy leaves room to share. Likewise, Meixing $(17, \mathrm{NC})$ suggests that privacy involves "certain thoughts or ideas that you keep only to yourself, or maybe someone else that is close to you, but it's relatively confidential." Both of their approaches to privacy highlight how privacy isn't simply binary access or no access - but, rather, control over how information flows or, in other words, control over the social situation. Maintaining control isn't necessarily about structural constraints. For example, Miguel $(17, \mathrm{NC})$ argues that privacy is "for someone to respect what you do." Taylor $(15, \mathrm{MA})$ takes this one step further by saying that privacy is "the right you have to keeping personal things private." By using the language of rights, Taylor makes it clear that privacy extends beyond the individual. What she's arguing for is the importance of social norms as a regulatory force.

In his seminal book Code and Other Laws of Cyberspace, Larry Lessig argued that four constraints serve regulatory purposes in society: the law, social norms, the market, and architecture (or "code" in the case of digital environments). ${ }^{11}$ Each of these four modes of regulation play a role in privacy, but when it comes to privacy in networked publics, social norms are often downplayed. Some scholars focus on the role that the law should play in regulating privacy in these new environments. ${ }^{12}$ Others lament the market's incentives for eroding privacy. ${ }^{13}$ Still others highlight how technology's code can be used both to destroy privacy and to protect privacy. ${ }^{14}$ When social norms are invoked, it's usually to justify approaches made by other

10 Gavison 1980, p. 421.

${ }^{11}$ Lessig, Lawrence. (2006). Code: Version 2.0. New York: Basic Books. Page 123.

12 Regan, P. (1995). Legislating Privacy. Chapel Hill: University of North Carolina Press

${ }^{13}$ Cohen, J. E. (2003). DRM and privacy. Communications of the ACM, 46, 46-49; Solove, D. J. (2004).

The digital person: Technology and privacy in the information age. New York: New York University Press.

${ }^{14}$ Zimmer, Michael. (2007). The Quest for the Perfect Search Engine: Values, Technical Design, and the Flow of Personal Information in Spheres of Mobility (PhD Dissertation, Department of Media, Culture, and Communication). New York University, New York. 
Paper to be presented at Oxford Internet Institute's "A Decade in Internet Time: Symposium on the Dynamics of the Internet and Society" on September 22, 2011.

regulatory forces. For example, when technology executives like Facebook's Mark Zuckerberg or Google's Eric Schmidt suggest that privacy is disappearing as a social norm, they are using this to justify the increased publicity of people's data on their services. ${ }^{15}$ Such incidents provoke people to respond by claiming that that the social norms aren't changing, and that privacy still matters. Of course, social norms are inherently unstable and constantly evolving; they vary widely and are difficult to pin down. Social norms are revealed when people talk about issues, and when their complex practices and attitudes are made visible. When it comes to privacy, social norms are evolving, but not disappearing, even as public figures attempt to downplay or diminish their power as a regulatory force. Teenagers are especially wedded to social norms as the only regulatory force they feel empowered to shape. This begs a critical question: in light of the powerful positions of the market, the law, and the architecture, how can social norms serve as a powerful regulatory force when it comes to privacy?

When trying to locate privacy, young people circle around the tropes that adults use to discuss privacy. They speak of secrets and trust, and highlight particular spaces as more or less private. Throughout these conversations, teens consistently come back to the importance of control and personal agency. They believe that privacy has to do with their ability to control a social situation, how information flows, and when and where they can be observed by others. Unfortunately, teens often struggle to assert control over situations, particularly when technology usurps their control or when their agency is undermined. More often than not, teens acknowledge this lack of control when people who hold power over them - e.g. their parents - insist on violating boundaries that teens create or social norms that they declare. Therein lies the key hypocrisy surrounding teens and privacy. Alongside adults' complaints that teens don't care about privacy when it comes to online activities is an ongoing belief that teens do not have the right to privacy when it comes to their physical spaces - or, in many cases, their online activities. ${ }^{16}$ Parents often use the accessibility of teens' online vocalizations as justification for violating teens' privacy.

In 2006, 17-year-old Bly Lauritano-Werner from Maine created a Youth Radio episode to highlight this hypocrisy. In it, she argued "My mom always uses the excuse about the internet being 'public' when she defends herself. It's not like I do anything to be ashamed of, but a girl needs her privacy. I do online journals so I can communicate

\footnotetext{
${ }^{15}$ See Esguerra, R. (2009). Google CEO Eric Schmidt Dismisses the Importance of Privacy. Electronic Frontier Foundation. Retrieved from https://www.eff.org/deeplinks/2009/12/google-ceo-ericschmidt-dismisses-privacy and Johnson, B. (2010, January 11). Privacy no longer a social norm, says Facebook founder. The Guardian. London. Retrieved from http://www.guardian.co.uk/technology/2010/jan/11/facebook-privacy.

${ }^{16}$ Marwick, A., Murgia-Diaz, D., \& Palfrey, J. (2010). Youth, privacy and reputation (literature review) (Berkman Center Research Publication No. 2010-5). Boston: Berkman Center for Internet and Society at Harvard University. Retrieved from

http://papers.ssrn.com/sol3/papers.cfm?abstract_id=1588163
} 
with my friends. Not so my mother could catch up on the latest gossip of my life."17 In doing so, Bly is arguing an age-old refrain; she wants the right to be let alone ${ }^{18}$ even - and perhaps especially - when she's socializing with friends.

Teens like Bly lack the agency to be able to assert social norms and adults regularly violate teens' understandings of social decorum. Consider what happened in Old Saybrook, Connecticut when local law enforcement and teachers put together an assembly for students on privacy. ${ }^{19}$ To make a point about privacy, the educators put together a slide show of images grabbed from students' Facebook profiles and displayed these images to the student body. Students were furious. One student told a reporter that this stunt is "a violation of privacy." Most adults find this incredulous given that the content was broadly accessible - and that the students in the school had already most likely seen many of these images because they certainly had access to them. Yet, by taking the images out of context, the educators had violated students' social norms and, thus, their sense of dignity, fairness, and respect. As one student explained to a reporter, "I kind of thought, it's like if you put it online, anyone can see it, but then at the same time, it's like kind of not fair for the police officers to put that on display without their permission and without them knowing." This incident does not reveal that teens don't understand privacy, but rather, that they lack the agency to assert social norms and expect that others will respect them. Those who have power over them - their parents and the police - can use their power to violate teens' norms, using accessibility as their justification. In this way, adults further marginalize young people, reinforcing the notion that they do not have the social status necessary to deserve rights associated with privacy.

In an era of social media where information is often easily accessible, it's all too easy to conflate accessibility with publicity. Yet, just because teens are socializing in a public setting doesn't mean that they want to be public figures nor does it mean that they want to be the object of just anyone's gaze. What's at stake concerns not just the right to be invisible, but who has the right to look, for what purposes, and to what ends. Finding a way to manage boundaries is just one of the challenges that teens face in navigating networked publics because privacy isn't simply about control over the social situation; it also requires enough agency to affect these situations.

As they enter into networked publics, teens are grappling with the tensions that surround privacy and publicity. They are trying to find ways to have agency and assert control in settings where both the architecture and their social position make

17 Youth Radio broadcast "Reading My LiveJournal” by Bly Lauritano-Werner: http://www.youthradio.org/oldsite/society/npr060628_onlinejournal.shtml ${ }_{18}$ Warren, S.D. \& Brandeis, L.D., (1890). Right to Privacy. Harvard Law Review, 4, 193.

19 Misur, S. (2011, April 11). Old Saybrook High School makes privacy point; Some perturbed when real students shown in social-media slide show. Shoreline Times. New Haven, CT. Retrieved from http://www.shorelinetimes.com/articles/2011/04/11/news/doc4da2f3cb5caae518276953.txt 
it very difficult for them to control the flow of information. Yet, in exploring strategies for maintaining social privacy in networked publics, they reveal how social norms are enacted. Privacy is both a social norm and a process; it is not something that is had so much as something that is negotiated. And the practices which teens engage in while attempting to negotiate privacy show that this social construct is not disappearing simply because technology introduces new hurdles.

\section{Life in (Networked) Publics}

Since they first became popular in 2003 , teens have flocked to social network sites to socialize with their friends. ${ }^{20}$ Social network sites have become the modern-day equivalent of the mall or movie theater, a place where teens can hang out with friends and run into other friends and peers. One way of understanding social network sites - and other popular genres of social media - is through the lens of "networked publics."

Networked publics are publics that are restructured by networked technologies. The notion of "a public" refers to both a highly accessible space where wide audiences can gather, and a collection of people who share what Sonia Livingstone describes as "a common understanding of the world, a shared identity, a claim to inclusiveness, a consensus regarding the collective interest." 21 Benedict Anderson argues that publics comprised of people who don't occupy a space, but rather a shared identity, can be understood as an "imagined community." 22 As such, a public is not a definable set of people or a bounded space, but a flexible category where people conceptualize boundaries but do not control them. Given this understanding, networked publics are simultaneously (1) the space constructed through networked technologies and (2) the imagined community that emerges as a result of the intersection of people, technology, and practice. Facebook, for example, serves both as a networked public itself and as a site upon which networked publics gather.

Publics serve multiple purposes. They can play a civic function, serving to gather people in a democracy. ${ }^{23}$ But they can also play a social role, enabling people to make sense of the world around them and understand their relationship to society. Hannah Arendt argues that "the presence of others who see what we see and hear what we hear assures us of the reality of the world and ourselves." 24 The

\footnotetext{
20 boyd, danah. 2007. Why youth (heart) social network sites: The role of networked publics. In Youth, identity and digital media, ed. D. Buckingham, 119-142. Cambridge, MA: MIT Press. 21 Livingstone, Sonia. 2005. Audiences and Publics: When Cultural Engagement Matters for the Public Sphere. Portland, OR: Intellect, 9.

22 Anderson, Benedict. 2006. Imagined Communities: Reflections on the Origin and Spread of Nationalism. New ed. New York: Verso.

23 Habermas, Jèurgen. 1991. The Structural Transformation of the Public Sphere: An Inquiry into a Category of Bourgeois Society. Cambridge, MA: MIT Press.

24 Arendt, Hannah. 1998. The Human Condition. Chicago, IL: University of Chicago Press, p. 50
} 
importance of publics for identity work and social conceptualization is precisely why teenagers seek out publics. Yet, given their marginalized position, they're often ostracized from the very publics that they wish to enter. Many physical sites of gathering explicitly or implicitly restrict teenagers; teens cannot enter bars because they are underage, they lack the economic resources to gather in eating establishments, and when teens gather in parking lots or on street corners, they're often accused of loitering. Given this, teens often seek to create their own publics; networked publics are, in many ways, teen publics.

Nancy Fraser noted that repressed groups often create "subaltern counterpublics" which, from a civic engagement perspective, can be understood as "parallel discursive arenas where members of subordinated social groups invent and circulate counterdiscourses to formulate oppositional interpretations of their identities, interests, and needs" 25 In considering the practices of queer individuals, Michael Warner found that counterpublics do not simply serve a civic role; queer individuals created their own publics for multiple purposes, including political resistance as well as engaging in identity work and negotiating social relations. ${ }^{26}$ The networked (counter)publics that teens create tend to emphasize sociable purposes, but they still serve a resistant purpose, challenging adult authority and norm-setting.

Participation in networked publics has become a core part of teen culture because teens value opportunities to gather with peers broadly, especially in situations where their interactions are not heavily configured by adults. They struggle for agency in networked publics, precisely because adults are ever-present in their lives. As physical spaces for peer sociability have disappeared or been restricted, and as teens have found their access structurally or socially curtailed, the value of mediated spaces where teens can gather has increased. In choosing where to go, the presence of peers and friends is the most important factor. If friends and peers gather in person, teens feel the need to be physically there to feel included. If the gathering takes place online, being online becomes socially critical. This sentiment is articulated by teens in terms of social expectations:

Skyler, 18, CO: Ifyou're not on MySpace, you don't exist.

Tara, 16, MI: Like everyone says get a Facebook. You need to get one.

Abigail, 17, NC: You're expected to be on Facebook. danah: How would people respond if you weren't?

\footnotetext{
${ }^{25}$ Fraser, Nancy. 1992. "Rethinking the Public Sphere: A Contribution to the Critique of Actually Existing Democracy." Pp. 109-142 in Habermas and the Public Sphere, edited by Craig Calhoun. Cambridge, MA: The MIT Press. (page 123)

${ }^{26}$ Warner, Michael. 2002. Publics and Counterpublics. Cambridge, MA: MIT Press.
} 
Abigail: People would ask you why. You'd have to have a good reason. If you didn't have a good reason people would be like you'd have to be like "the internet at my house isn't working." But if you didn't have a good reason like "I'm just not on it." People would be like "Why not? Get on it. Make an account." You don't have to pay for it so I feel like people feel there's any reason not to be. It's pretty much expected you're on Facebook.

While teens use Facebook and MySpace as communication channels, they also use them as networked publics, relishing the opportunity to connect to a broader community of people. At the same time, they're not interested in connecting to just anyone. Through the public articulation of "Friends" on social network sites, teens construct the boundaries of their imagined community. As with all publics, there's porousness to this formalization. While some teens have a rigid sense of boundaries, others relish the possibility of connecting beyond their nearest and dearest; this is what motivates them to engage in a networked public rather than just communicating via text message with their close friends. Emily, a 16-year-old from Pennsylvania, explains the cultural logic of this when she points out that the social possibilities of going to the mall or movies are far greater than going to a friend's house:

"If you go [out] with your friends, there might be other people you run into that are your friends too. I would say it's more of an opportunity to see more of your friends than just going over to a friend's house. Going over to a friend's house, there might be one friend or maybe three. Whereas going to the mall, it can be seven or twelve."

The same logic holds for networked publics. Teens use social media to get to know people who are more acquaintances than friends or to meet friends-of-friends. A small minority of teens seek out broader audiences, welcoming strangers who seem to share their worldview. Yet, even teens who welcome broad audiences do not assume that they are publicizing information to all people across all space and all time when they engage in networked publics.

\section{How Architecture Inflects Practices}

While networked publics can serve the same social roles as other publics, the affordances of networked technologies present new challenges that inflect the social dynamics that play out in networked publics. In particular, four affordances play a significant role in reconfiguring public sociality:

- Persistence: Digital expressions are automatically recorded and archived.

- Replicability: Digital content is easily duplicated.

- Scalability: The potential visibility of digital content is great.

- Searchability: Digital content is often accessible through search engines. 
Because of these technical affordances, participation in networked publics requires regularly contending with dynamics that aren't commonplace in everyday life. For example, although journalists are accustomed to writing for invisible audiences, this is not typically how people relate to others when they're socializing. Yet, in networked publics, people must grapple with what it means to participate in a social situation where they have no way of fully understanding who is - and who is not observing their performances. Just as journalists imagine their audience when they craft a story, so too must teens imagine their audience whenever they post something on Facebook.

Another dynamic that teens must navigate is the commonplace collapsing of social contexts. While countless movies have been made about situations where contexts collide in everyday life - e.g. running into your ex when out on a date - these are considered exceptional moments. Yet, in networked publics, it is exceptionally difficult to separate contexts. The flattening of diverse social relationships into a monolithic group of "Friends" makes it difficult for users to negotiate the normal variances of self-presentation that occur in day-to-day life. Social media participants regularly lament moments where worlds collide. ${ }^{27}$

A third dynamic brought on by the technological affordances common to networked publics has to do with the blurring of what is public and what is private. As social constructs, privacy and publicity are affected by what is structurally feasible and socially appropriate. In recent history, privacy was often taken for granted because structural conditions made it easier to not share than to share. Social media has changed the equation.

In unmediated interactions, we assume a certain amount of privacy simply because it takes effort to publicize interactions. When we share updates about our lives over coffee, we don't expect our interlocutors to share them widely, because 1) we don't believe that said information is interesting enough to be spread widely; 2 ) it's difficult to disseminate social information to a large audience in face-to-face contexts; and 3) recording a conversation or sharing every detail of an interaction would violate both social norms and the trust assumed in a relationship. If we do believe that our interlocutor might be interested in sharing what we said, we explicitly state that the interaction is private and expect the social norms around the conversation to triumph. ${ }^{28}$ And if our interlocutor wants to publicize every detail, it is assumed that this intention will be announced (e.g., a journalist interviewing an expert). Furthermore, people who are likely to share as much as they can remember are often labeled as "gossips" - often because they initially violated the social norms around sharing and are no longer trusted. Everyday social dynamics are predicated

\footnotetext{
27 Marwick, Alice, and danah boyd. 2011. "I tweet honestly, I tweet passionately: Twitter users, context collapse, and the imagined audience." New Media \& Society 13 (1): 114-133.

28 This does not mean that such violations never occur. Linda Tripp's recordings of Monica Lewinsky confiding in her are an example of how violations do occur.
} 
Paper to be presented at Oxford Internet Institute's "A Decade in Internet Time: Symposium on the Dynamics of the Internet and Society" on September 22, 2011.

on the notion that most interactions are private-by-default, public-through-effort. The default is private, not because it needs to be but because effort is required to actually make things visible.

With social media, the opposite is assumed. The very act of participation in networked publics makes content widely available to many interested parties, effectively the relevant "public." Rather than choosing what to include or what to publicize, most teens think about what to exclude. They accept the public nature of information, which might not have been historically shared (perhaps because it was too mundane), but they carefully analyze what shouldn't be shared. Disclosure is the default because participation - and, indeed, presence - is predicated on it.

Technology may not be radically altering teens' desires, but it does complicate how they navigate privacy. Consider how 17-year-old Alicia from North Carolina understands privacy with respect to Facebook:

"I just think that [technology is] just redefining what's acceptable for people to put out about themselves. I've grown up with technology so I don't know how it was before this boom of social networking. But it just seems like instead of spending all of our time talking to other individual people and sharing things that would seem private, we just spend all of our time putting it in one module of communication where people can go and access it if they want to. So it's just more convenient. I think that the adults think that about privacy because when they see pictures being put up or things they never had that ability. So when they see [our photo albums] or when they see conversations on Facebook wall to wall, they think that it's this huge breach of privacy and your personal ideas or whatever... Like I said earlier, there are things you shouldn't put up or you shouldn't say. But I think privacy is more just you choosing what you want to keep to yourself. ... And so I don't think that Facebook is violating privacy. I think it's letting people choose how they want to define privacy."

Alicia recognizes that how she approaches sharing is different from those who grew up in an earlier era; she also recognizes that this is rooted in technological affordances. How she approaches navigating privacy in Facebook also demonstrates that the nature of privacy and publicity in public life is shifting. Rather than seeing privacy as the default, Alicia sees privacy as a conscious choice. In her interactions online, she assumes that Facebook is public-by-default, privatethrough-effort. She highlights how this model of privacy is located in another change, facilitated by the affordances of Facebook, as her peers move from sharing directly to sharing abstractly. In other words, what Facebook enables is the ability for users to share information for others to consume when and as appropriate understood in technology circles as "pull" - as opposed to having to directly target specific people, or "push." A public-by-default environment doesn't just reconfigure how privacy is managed, but the very nature and dynamic of sharing. 
The affordances of networked publics shape social dynamics, but they do not determine them. How teens negotiate privacy in networked publics varies tremendously, shaped not only by the underlying architecture of the software, but also young people's personal values and social norms that surround them.

\section{Variations in Privacy Norms and Practices}

Even though all the teens we interviewed expressed an appreciation for privacy at some level, they did not share a uniform set of values about privacy and publicity. Just as some teenagers are extroverted and some introverted, some teens are more exhibitionist and some are more secretive. Variations among individuals are shaped by local social norms; sharing is viewed differently in different friend groups, schools, and communities. There's also a gendered component to it, with teens having different ideas of what is appropriate to share that map to stereotypical understandings of male and female emotional behavior. When 17-year-old Manu emphasizes that he's "not that kind of person," he's also enacting fairly widespread norms of masculinity:

danah: When you broke up with your girlfriend, did you write anything about it on Facebook?

Manu, 17, NC: No. I'm like-- I'm not that kind of person-- I find it really weird to have my emotions or anything on Facebook or Twitter, and it's just-- I don't do stuff-- I know other people do, but I feel like I'll get judged or just-- I'm not that kind of person to let stuff out like that. I don't do statuses, actually, either.

Privacy must be contextualized. Teen understandings of privacy and how they carry these out varies by individual, by community, by situation, by role, and by interaction. In other words, privacy - and the norms surrounding privacy - cannot be divorced from context. ${ }^{29}$

When teens share information about themselves, thereby increasing their exposure, they do so because they gain something from being visible. There is always a tradeoff, as teens account for what they might gain and what they might lose and how such cost-benefit analyses fit into their own mental models of risk and reward. Thus, when teens are negotiating privacy, they aren't simply thinking about a "loss"; they're considering what they might gain from revealing themselves.

Consider the words of Meixing, a bubbly 17-year-old from Tennessee who shares extensively on Facebook:

Meixing, 17, TN: Most of the time I'm a pretty extroverted person so I share a lot of things with people anyways... danah: That means you don't care about privacy?

${ }^{29}$ Nissenbaum 2010. 
Paper to be presented at Oxford Internet Institute's "A Decade in Internet Time: Symposium on the Dynamics of the Internet and Society" on September 22, 2011.

Meixing: I mean I do care about privacy, but if I found someone that I could trust then my first instinct would be to share stuff with that person. For example, I think, like my last boyfriend and I we were really close and then we had each other's passwords to Facebook and to emails and stuff. And so if I would get something that I didn't know about then he would notify me and look over my stuff... It made me feel safer just because someone was there to help me out and stuff. It made me feel more connected and less lonely. Because I feel like Facebook sometimes is kind of like a lonely sport, I feel, because you're kind of sitting there and you're looking at people by yourself. But if someone else knows your password and stuff it just feels better.

Meixing is highlighting the trade-offs that she faces when she's thinking about privacy. On one hand, she cares about privacy, but she's willing to expose herself in intimate situations because it makes her feel more connected. Her barriers to sharing are rooted in her sense of trust. She's not willing to expose herself to just anyone; she shares both because and as a signal that she trusts someone.

Trust is a very significant issue for teenagers and it regularly emerges in discussions about privacy. Many teens aren't confident that they can trust those around them, even their closest friends. All too often, teens use the information that they gather about others to "start drama," performing gossip and social conflict for a wide audience on social media. ${ }^{30}$ This makes some teens very nervous about sharing, even with their closest friends. Taylor, a 15-year-old in Massachusetts, questions the motivations behind her friends' decisions to invade her privacy.

Taylor, 15, MA: So I usually give people the light version because I don't want them in my business and I really don't think that they have any right to be in my business. danah: Why do they think they have a right? Taylor: Because they're my friends, so they put themselves in my business sometimes, so they think that they should be there to help me and protect me with things but I can deal with it myself.

Taylor doesn't want her friends "in her business" because she's worried that she'll lose control, so she purposely avoids sharing anything that is personal or intimate. But this doesn't stop her from sharing altogether. A photographer, she regularly uploads her work to Facebook precisely because she wants feedback and public validation.

Taylor, 15, MA: [A comment] gives me input and it makes me feel good. ... Even if it's negative I'd probably like it as a comment. It's just like a message is more personal, which I appreciate, but when people can see that they like my work, I like it when people can see that other people like it because I don't know, I just like getting lots of comments on one picture and seeing people read them.

\footnotetext{
30 Marwick, Alice and boyd, danah. (2011). "The Drama! Teens, Gossip and Celebrity." Popular Culture Association/American Culture Association Annual Meeting, San Antonio, TX, April 20-24.
} 
Paper to be presented at Oxford Internet Institute's "A Decade in Internet Time: Symposium on the Dynamics of the Internet and Society" on September 22, 2011.

In choosing to share her photographs but not her personal thoughts, Taylor is trying to assert control, thereby enacting privacy by selecting what should and should not be shared. She is not alone in this approach. Many teens who seemingly share a lot online are actually consciously limiting what is available. Consider Abigail's perspective:

Abigail, 17, NC: I actually know everybody I'm friends with [on Facebook]... But I'm not good friends with everybody on Facebook. The people that I go to school with I know I know what they're doing. That's why I'm friends with them on Facebook but they don't need to know what I'm exactly doing today. I'm eating breakfast, then I'm going to swim practice, then I'm doing my history homework, then I'm going to do this. They don't need to know all that. I can just put an overview like "Practice, homework, then Allie's, "or something. I don't need to say exactly everything I'm doing at times and stuff.

The affordances of networked publics that make widespread sharing possible also motivate teens to use more private channels of communication - like text messaging or Facebook chat - to discuss things that are embarrassing or upsetting, intimate or self-exposing.

Although most teens are quite conscious about what they choose to share, they don't always have complete control over what others share about them. Facebook, Flickr and other social media sites let users tag pictures of other users, while Twitter creates affiliations between users through @replies. In North Carolina, 17-year-old Jacquelyn finds it "weird" and embarrassing that her mother regularly posts pictures of her on Facebook. While she's uncomfortable with her mother sharing photos of her, she also understands the impulse. "I guess as a parent, it's different than being a teenager because we're her kids so she wants to show all her college friends and high school friends what we're up to because obviously, we're not going to friend her high school friends because we don't know them. It makes sense, I guess. I don't know."

In trying to navigate privacy, teens must not only contend with what they choose to share, but what others choose to share about them. While networked privacy is not unique to networked publics, the affordances of networked publics magnify this issue, reifying the public-by-default nature of such environments. Those who are more inclined to share often expect those who don't want information shared to speak up. Abigail, for example, posts all photos from her camera to Facebook because it's easier for her than filtering. She goes through her photo albums and tags the photos with her friends' names, deleting any photos that are blurry. Most of the pictures she puts up have multiple people in them, so she's not inclined to delete them, but understands if her friends untag themselves. If a friend is "really bothered" by a photo and complain to her directly, she'll delete it. The assumption 
in Abigail's friend group is that content is public-by-default. Such a setting forces teens to make a conscious choice about what to obscure, rather than what to publicize.

The public-by-default nature of networked publics is especially acute on Facebook and Twitter because of the role that social streams play in those environments. Facebook's news feed broadcasts both implicit actions (e.g., a broken heart when two people stop being "in a relationship") and shared content (e.g., newly uploaded photographs). The news feed and Twitter's stream are central to those sites and the first thing that most participants see when they login. While Facebook's news feed was controversial when it first launched, ${ }^{31}$ it's now a fundamental part of Facebook's architecture. Teens share updates to be seen by their friends, but they also recognize that not everything shared through this mechanism is actually seen by their friends. While some teens expect their friends to read every update and picture that they post, others see the public-by-default dynamic as an opportunity to reduce expectations. Consider why Vicki, a 15-year-old from Georgia, posts status updates in lieu of sending private messages:

Vicki, 15, GA: Because a status update, everybody can read. Like, everybody who wants to read it can read it, but they're not obligated to read it. Like, when you send a message, it's, "Oh my gosh, this person sent me a message. Now I have to read this." But, when it's an update, it's, like, if I don't want to read your status, I'm not going to read yours. But I'm going to read the next person's, like, if I want to read theirs. You don't have to look at it if you don't want to.

Content that is publicly accessible is not necessarily universally consumed. Likewise, information that is publicly accessible is not necessarily intended to be consumed by just anyone. While teens may be negotiating privacy in a public-bydefault environment, social norms also serve a critical role in how teens do boundary work.

\section{Boundary Work}

Traditionally, realms of "private" and "public" have been built upon a set of dichotomies and divisions, whether they be spatial (workplace, home), temporal ("on" or "off" the clock), or object-related (work BlackBerry or parent's car). These distinctions must be reinforced and re-inscribed through a series of processes, which Michèle Lamont and Virág Molnár refer to as "boundary work."32 Boundary

\footnotetext{
31 boyd, danah. 2008. "Facebook's Privacy Trainwreck: Exposure, invasion, and social convergence." Convergence: The International Journal of Research into New Media Technologies 14 (1): 13-20.

${ }^{32}$ Lamont, M., and V. Molnar. 2002. "The study of boundaries in the social sciences." Annual Review of Sociology 167-196. Christena Nippert-Eng extended this notion of boundary work to individual's boundaries around privacy. See Nippert-Eng 2010 pp. 10-14.
} 
work creates symbolic distinctions between objects, people, practices, and architectures-a teen's car is "private" yet their parent's is "public."

Creating, maintaining, and managing boundaries is difficult and requires various interpretive strategies, traditions, and distinctions to achieve. Teens attempt to achieve social privacy through a variety of strategies, demonstrating how they understand architecture, assert norms, and attempt to bring their definition of privacy into existence. Defining and inscribing boundaries is one way to regulate a set of spaces that do not fit neatly into categories of "public" or "private." Whether these techniques are successful, problematic, or both, they demonstrate the ways that teenagers are engaging in boundary work by necessity.

The most common way in which teens try to delineate boundaries is through the assertion of social norms. Teens have an implicit understanding about who should and should not be present in their social spaces. When MySpace was the dominant social network site, teens would regularly voice frustration with adults who didn't seem to understand that MySpace was "my space." In other words, teens were emphatic that parents and other adults were supposed to know that they weren't welcome. Many young people felt that there was an implicit "keep out" sign on MySpace, meant to signal that adults weren't welcome. To reinforce this, teens focused on explicitly articulating who they imagined as part of their networked public through the public articulation of "Friends." 33 Teens displayed their closest friends through the "Top 8" list, which appeared on every MySpace profile and indicated affiliations and social context. In this way, they wrote their intended audience into being so that it could serve as a signal to any who happened across their profile. Yet, even parents who might respect such a sign on a bedroom door, often failed to recognize or respect such signals online. In other words, even as teens were trying to assert social norms, their efforts were ignored; some adults fail to recognize the cues that youth are signaling while others judge teens' practices on their own terms, refusing to recognize teens' agency.

As social network sites became more widespread - and as adults started using Facebook and MySpace for reasons other than surveilling their children - some teens started accepting the presence of their adults, while others found it awkward. When I asked Aarti how she felt about her mother looking at her Facebook profile, she said:

Aarti, 17, NC: I guess it's not that bad, because I wouldn't really do anything bad, but it's kind of annoying. But, you know, she's looking. ... I think it's just weird. Because my mom-- I just think Facebook is for my friends, and not my mom.

33 boyd, danah (2006). "Friends, Friendsters, and MySpace Top 8: Writing Community Into Being on Social Network Sites." First Monday, 11 (12). 
Paper to be presented at Oxford Internet Institute's "A Decade in Internet Time: Symposium on the Dynamics of the Internet and Society" on September 22, 2011.

Aarti's message highlights how privacy and boundary work come together. Privacy for Aarti is about controlling the social situation, not about hiding things from her mother. Daniel Solove calls this the "nothing to hide" model of privacy and vociferously argues that privacy is a larger value which "allows people freedom from the intrusiveness of others." 34 Nevertheless, the prevalence of this view-that you only need privacy if you're doing something you shouldn't-leads many teens, when talking about their desire for privacy, to disclaim that that they aren't being "bad." Aarti's desire for privacy from her mother isn't rooted in her feelings of needing to hide, but rather her desire to have control over the social situation. Aarti feels as though her mother should understand that Facebook isn't meant for her. Likewise, when I asked Chantelle about how she'd feel if her teachers looked at her profile, she said:

Chantelle, 15, DC: I'd be like 'Why are they on my page?' I wouldn't go to my teacher's page and look at their stuff, so why should they go on mine to look at my stuff?... I mean, they're not going to find nothing.

What these teens are trying to vocalize is that social network sites should have understood boundaries, driven by a collective understanding of social contexts. Yet, online, teens are regularly facing "collapsed contexts" as friendship and family, school and home collide. ${ }^{35}$ Teens struggle to manage these different contexts simultaneously, but they recognize that different contexts typically involve different self-presentations.

Carmen, 17, MA: At least with me, you act differently around different people. Everyone I know, they act a certain way around certain people. And sometimes you only want them to know that part of you I guess. And if you have privacy I think they only see the side that you show, where if you don't have privacy then they see everything.

Young people recognize that privacy isn't a universal value, but something that's rooted in an understanding of context. The issue for them is not about who can physically access the content, but who should be present with them and what is socially appropriate given those people and given that context. To reinforce this expectation, teens use a broad variety of linguistic and structural signals. While early users of MySpace tried to signal boundaries on social network sites by carefully choosing who they friended, parents often forced their children into friending them as a condition of using the service, devaluing the Friends list as a signal of the intended audience. Facebook opened up to colleges and high schools before the general public, creating a structural boundary that is now defunct. Today, many teens use language to signal boundaries, attempting to clearly mark Facebook as a space for friends by using casual language, social photos, in-jokes, cultural

${ }^{34}$ Solove, Daniel J. (2007). "I've Got Nothing to Hide' and Other Misunderstandings of Privacy." San Diego Law Review 44: 762.

35 For a more detailed discussion of collapsed contexts, see Marwick and boyd (2011b). 
Paper to be presented at Oxford Internet Institute's "A Decade in Internet Time: Symposium on the Dynamics of the Internet and Society" on September 22, 2011.

references, and other styles of sharing that teens use when they are with each other. Unfortunately, many adults fail to recognize these strategies as signals, instead projecting their own values onto teens' practices and judging teens through their worldview.

Hunter is a geeky 14-year-old living in inner city Washington DC. His mom moved from Trinidad when his older half-siblings were quite young because their father was abusive. Hunter's mother and father are not together, but Hunter has a relationship with his father, unlike his older (and, for that matter, younger) siblings. Hunter sees himself as very different from his siblings and cousins, who he identifies as "ghetto." In his words, this means "not really caring about what people think about you... [not caring] about being smart or having good grades... always getting into trouble, because you want to start trouble, not 'cause you can't avoid it." To describe how his sister "became" ghetto, he explains, "her boyfriend, he doesn't treat her well, and she has a baby now, and, every time they have a fight, she cuts off her phone, she disconnects her phone or, if it's disconnected, she doesn't want to talk to my mom, 'Oh, I'm not feeling well,' but she's always on Facebook and always posting all kinds of nonsense on Facebook which is one of the things my mom gets so upset about." Although Hunter laments her choices, he very much loves his sister and wants her in his life, even though his mother worries that she's a bad influence on him. Hunter feels confident about who he is - a geek who is proud of his intellectual curiosity and prowess and who is gratified to be an honor student at a competitive high school. Of course, he also recognizes that none of his family members, other than his mom, value his academic achievements, esoteric tastes, or passion for reading.

On Facebook, Hunter is "friends" with his sister and cousins as well as his friends from school; the context collisions that occur on the site are a constant source of tension for Hunter. He tries to make it clear that certain status updates are meant for certain people, but his family members regularly miss these signals, making it hard for him to manage social boundaries on Facebook.

Hunter, 14, DC: When I'm talking to my friends on Facebook or I put up a status, something I hate is when people who I'm not addressing in my statuses comment on my statuses. In [my old school], people always used to call me nerdy and that I was the least black black person that they've ever met, some people say that, and I said on Facebook, "Should I take offense to the fact that somebody put the ringtone "White and Nerdy" for me?" and it was a joke. I guess we were talking about it in school, and [my sister] comes out of nowhere, "Aw, baby bro," and I'm like, no, don't say that, I wasn't talking to you.

danah: How do people know who is being talked to with Facebook status updates? Hunter: I guess that is a point. Sometimes it probably is hard, but I think it's just the certain way that you talk. I will talk to my sister a different way than I'll talk to my friends at school or from my friends from my old school, and I might say, "Oh, well, I fell asleep in Miss K's class by accident," and they'll say, "Oh, yeah, Miss K is so boring," and 
Paper to be presented at Oxford Internet Institute's "A Decade in Internet Time: Symposium on the Dynamics of the Internet and Society" on September 22, 2011.

she's like, "Oh, well, you shouldn't fall asleep. You should pay attention." I mean, I think you can figure out that I'm not talking to you if I'm talking about a certain teacher.

Hunter's story highlights how teens attempt to assert social norms, and fail. Unable to manage boundaries through the assertion of social norms, teens often begin experimenting with structural and social strategies to achieve privacy.

\section{Structural Strategies}

Frustrated by his sister and cousins' failure to understand what he perceived as acceptable social norms, Hunter decided to take a different tactic to manage the collapsing of contexts - he started to use Facebook's blocking feature as a way to directly limit their participation. For example, his cousins make fun of his preference for Pokémon or Legends of Zelda over shooter games. So when he posts about video games, he explicitly blocks his cousins so that they won't post negative comments about his enthusiasms that he would find "embarrassing." By explicitly blocking people, he can segment his audiences. But he also knows that this is not foolproof and that, if his cousins were to find out, they would be quite upset. In his mind, his only other alternatives are to de-friend them or delete their content; neither approaches appeal to him, so he's hoping that they won't accidentally see that he's posting content that they can't see. The social pressure against defriending is acute to the point where teens will engage in elaborate strategies to avoid it.

Facebook has numerous technical features that can be used to segment audiences and limit the visibility of information. While teenagers do use these features ${ }^{36}$, they often have mixed understandings and faith in them. On one hand, teens generally believe that they can use Facebook's privacy settings to keep strangers - or "creepers" - out; this is often what motivates them to actively configure their settings in the first place. Of course, as Brandimarte, Acquisti, and Loewenstein have noted, this "illusion of control" is what motivates Facebook users to share more with the service in the first place; users believe that they have kept strangers out while remaining unaware of who else might have access to that data (such as Facebook themselves). ${ }^{37}$ While teens generally do not account for invisible third parties, they do account for eavesdroppers and gossipmongers. From this perspective, most young people are not convinced that Facebook's privacy settings will actually help them control how information flows. As eavesdroppers themselves, they've witnessed content leaking when someone's friend posts a response or references a post. And they're fully aware that friends and parents are

36 boyd, danah and Eszter Hargittai (2010). "Facebook Privacy Settings: Who Cares?" First Monday 15 (8).

37 Brandimarte, L., Acquisti, A., and Loewenstein, G. (in review) "Privacy Concerns and Information Disclosure: An Illusion of Control Hypothesis." 
Paper to be presented at Oxford Internet Institute's "A Decade in Internet Time: Symposium on the Dynamics of the Internet and Society" on September 22, 2011.

looking over people's shoulders, accessing information in ways that cannot be controlled through Facebook's privacy settings. Thus, teens have started developing innovative structural strategies for achieving privacy that don't rely on Facebook's privacy settings.

One of the most common strategies that both teenagers and adults use is to separate social contexts by social tool. For instance, some teens used Facebook and MySpace to talk to different social cohorts. For a while, teens would create separate MySpace profiles for separate purposes; this practice was rendered obsolete by Facebook's insistence on one account per user and, more importantly, by the recommended Friends feature on Facebook that regularly outted people's second profiles.

Most of the teens we interviewed used multiple communication channels and considered them as having different purposes. For example, teens would argue that Facebook was more public-facing, while text messaging was more intimate. These distinctions were not always driven by the technical affordances of the modalities as much as the social practices that had grown up around them. When 17-year-old Manu from North Carolina explained that, "Facebook is like yelling out to a crowd while Twitter is just like talking in a room," it was not because Twitter is inherently more private than Facebook, but because his peers, parents and community had not broadly adopted it. Twitter served a more intimate role for Manu than Facebook, at least for the present time. Segmenting friend groups by service is relatively common, but this is difficult to maintain, especially given the dominance of Facebook in the lives of the teens we interviewed.

Two of the more unique strategies we found for achieving privacy were described by 18-year-old Mikalah and 17-year-old Shamika in Washington DC. Both girls have limited literacy, but extensive street smarts. Although unwilling to talk to us about it, Shamika had Mikalah's name tattooed on her arm and her Facebook profile made it clear that they were in a relationship. Both girls were extremely cagey and nervous to talk with us; Shamika opened up more about herself than Mikalah. But each described unique strategies for dealing with Facebook.

To Alice, Mikalah described that she deactivated her Facebook account every day after she was done looking at the site. Deactivation was introduced by Facebook as an alternative to deletion; users could deactivate their content and for all intents and purposes would disappear from the site, but if they later regretted it could reactive their account and retrieve all of the content, connections, and messages. Mikalah did this every day, which in effect made it so that her friends could only send messages or leave comments when she was logged in. Through this mechanism, Mikalah turned Facebook into a real-time service, obliterating both the benefits as well as the consequences of asynchronicity. She knew that adults would try to look at her profile during the daytime and she didn't want to be searchable; she regularly had to deal with the state and didn't trust adults. But she reasonably 
assumed that most adults would be less likely to be looking for her at night when she got online. Thus, in effect, she created an invisibility cloak for her Facebook usage - letting her stay visible to those that could see her when she was around and being invisible to the prying eyes of those in power who were looking for her when she wasn't around.

Shamika took a different approach. As she explained to danah, she found that Facebook contributed to drama by providing a plethora of past comments that could be used against people whenever a friendship or relationship turned sour. Thus, she preferred to minimize her risk by deleting every comment she received after she read it. Furthermore, she'd write a comment on someone else's page and then delete it the next day, presumably after they had seen it. Shamika's constant deletion turned Facebook into a more ephemeral space, destabilizing the persistent nature of the space. While Shamika fully understood that people could save her posts, she felt that the extra hurdle was the difference between normal and creepy. For her, this act of deletion meant a reduction in conflict, and she was trying to stay out of trouble because she had received several school suspensions already. The less information that was out there for jealous peers to misinterpret, the better. For Shamika, Facebook is a "light touch" communication structure, meaning that she can check in with what's happening with her community without having to have a deep emotional investment; this is very important to her. But it doesn't need to be persistent to be useful.

While technical strategies to limit access can be helpful, these techniques are not foolproof. The affordances of networked publics create slippages. Many teens have stories of when something thought to be relatively "private" on Facebook leaked beyond its intended context. Whether due to parents watching over the shoulder or friends copying and pasting status messages, the technologies do not provide accurate indicators of what is visible to whom, highlighting how controlling access is not always the best course.

\section{Social Strategies}

Recognizing that social norms and structural limitations are often ineffective, many teens take a different tactic to achieve social privacy: they limit the meaning of their messages. This is not a new strategy for the digital era, nor is it something reserved solely for teens, but the complexity of achieving privacy in networked publics has motivated countless teens to act assuming that they are being surveilled. In Massachusetts, 17-year-old Carmen regularly struggles to manage her mother's misinterpretations of everything she says on Facebook. In short, Carmen's mother has a tendency to overreact. Furthermore, she has a tendency to reveal her overreactions in the form of Facebook comments.

Carmen, 17, MA: [My mother] tends to comment on everything. I'm like, go away. danah: Do you ever delete her comments? 
Paper to be presented at Oxford Internet Institute's "A Decade in Internet Time: Symposium on the Dynamics of the Internet and Society" on September 22, 2011.

Carmen: No, because then I feel bad. I don't want to feel bad. She's gotten better, now she just sends me messages.

danah: Why don't you want her commenting?

Carmen: Because then it scares everyone away. Everyone kind of disappears after the mom post. ... And it's just uncool having your mom all over your wall, that's just lame.

Carmen loves her mother and likes that her mother cares about what's happening in her life, but these overreactions can be stifling. When Carmen broke up with her boyfriend, the relationship wasn't working but she was still sad. She wanted her friends to know how she was feeling, but she was afraid that if she posted a moody message to Facebook, her mother would assume she was suicidal. She didn't want to upset her mother, so rather than posting a sappy message, she chose to post lyrics from "Always Look on the Bright Side of Life." Her geeky friends immediately recognized the song from "Life of Brian" and knew that the song was sung when the main character was about to be executed. Her mother, on the other hand, did not realize that the words were a song lyric, let alone recognize the Monty Python reference. She took the words literally and commented on Carmen's post, noting that she seemed to be doing really well. Her friends, familiar with the Monty Python reference - and witnessing Carmen's mother's misinterpretation in her comment texted her to get the full story.

By encoding her message so that only her friends can decode the meaning of it, Carmen is engaged in an act of "social steganography." Steganography is an age-old tactic of hiding information in plain sight, driven by the notion of "security through obscurity." 38 Stegnographic messages are sent through channels where no one is even aware that a message is hidden. For example, in the ancient Greek text "The Histories," Demaratus hid a message in the wood beneath the wax of a wax tablet while Histiaeus tattooed a message on a slave's head that was rendered invisible when his hair grew. In both cases, the message was easily accessible but required knowing that a message existed in the first place. ${ }^{39}$ Such techniques are also part of contemporary children's play with toys like invisible ink pens. Steganography isn't powerful because of strong encryption; it's powerful because people don't think to look for a hidden message. The meaning behind Carmen's song lyrics post is, for all intents and purposes, invisible. To anyone reading the message, it simply looks like a happy post. And even if the reader recognizes it as song lyrics and understands the Monty Python reference, they don't understand the full implications unless they're close enough to Carmen to know that she just ended the relationship with her boyfriend. Unlocking the meaning of that post requires recognizing multiple referents.

\footnotetext{
38 Petitcolas, Fabian A. P., Ross J. Anderson, and Markus G. Kuhn. (1999, July). "Information Hiding: A survey." Proceedings of the IEEE (special issue on protection of multimedia content) 87 (7): 106278. 39 Ibid.
} 
While some teens choose to hide in plain sight, others post encoded messages intended as visible displays of in-jokes or obscure referents, or are meant to encourage certain people to respond while isolating others. In North Carolina, 17year-old Jacquelyn posted a simple message on her Facebook: "Yes!" As a premier ballerina, she was regularly competing for roles with another ballerina who she did not particularly like. She regularly complained about this to her close friends. When the second ballerina decided to leave the company, Jacquelyn immediately wrote "Yes!" on her Wall. She understood that her closest friends would probably guess what had just happened and that anyone who was close to her would approach her in-person or via text message to ask her what the good news was. She also knew that if she was asked about the message by anyone she didn't want to share the gossip with, she could offer an alternative explanation to the seemingly innocuous message. Plausible deniability is an important part of this strategy.

Jacquelyn didn't want to start any drama, which is why she was intentionally opaque about her message, but other teens use this strategy to create conflict. As Camille explains:

Camille, 17, NC: If you're talking about somebody on Facebook, they can see it... not directly talking about somebody, but talking about them without using their names, and then, they'll start talking about them without using their name, and it's obviously they know they're making fun of each other.

Alice: How would you talk about someone without using their name?

Camille: Like everybody will use a quote that somebody said, and then they'll be like, that's so stupid or something, who is she, and then another person will say it, and then they'll, like, respond to something else, and kind of making fun of them indirectly, fighting.

Alice: So why do you think someone would do that?

Camille: I don't know, it's drama, kind of entertaining.

In North Carolina, danah was going through Facebook with 17-year old Serena when she stumbled on a status update written by Kristy. Kristy's update said: "I'm sick and tired of all of this" and was already "Liked" by more than 30 people. Unable to interpret the post, danah asked Serena to explain. Serena began a lengthy story of how Kristy was fighting with another girl, Cathy, over a boy. Cathy had written "She's such a bitch" on her Facebook wall, which was liked by a whole host of Cathy's friends. Kristy had posted this message in response, and now Kristy's friends had backed her by liking the update. Serena was a bystander in this argument, but she knew how to interpret each message; danah, as an outsider, did not. Cathy and Kristy are performing for others to see, but they are also limiting the meaning to those who are in the know. In doing so, they can exclude people who are not part of the cycle of gossip at school, namely parents, teachers, and peers outside of their immediate social sphere. 
Paper to be presented at Oxford Internet Institute's "A Decade in Internet Time: Symposium on the Dynamics of the Internet and Society" on September 22, 2011.

When teenagers post encoded messages, they know that people outside of their intended audience will be curious. Some will investigate, while others will be upset. Still others find the uninterpretable content frustrating because it clogs up Facebook.

danah: And how do you feel about things that you don't understand? Jenna, 17, NC: It depends who it is. If it's someone that I want to know what they're talking about then I'll try to investigate it. I'll look at the wall, a conversation or something. But if it's like that I don't really care what so-and-so is doing. I have friends from when I went to Malaysia. They were all about Facebook. So I have 50 friends from Malaysia now. And sometimes I hide them because whatever they're talking about is confusing to me because I don't know what they're talking about or I get stuff from them that I don't really want.

Some teens view encoded messages as secrets meant to be decoded; they relish the opportunity to eavesdrop. Yet, for the most part, many young people see such messages as none of their business, choosing to ignore them. Similarly, plenty of teens believe that just because a message can be seen doesn't mean that others should be looking. They expect people to ignore what's not meant for them.

These acts of encoding messages are a way of asserting control over a social situation, but they do not always achieve their intended effect, particularly when peers are curious and nosy. In Massachusetts, 17-year old Kelly was unhappy about her relationship but didn't have the nerve to break up with her seriously depressed boyfriend. To set the stage for doing so, she started posting morbid messages and unhappy "emo" lyrics to her Facebook. Her friends knew what she was up to and didn't confront her about it, but a girl in her class that she didn't know very well took these messages seriously and notified their guidance counselor that Kelly might be suicidal. Kelly was irritated because she felt that those messages were meant for those closest to her, not people she barely knew.

Many teens have started to realize that limiting access to meaning can be a more powerful tool for privacy than trying to limit access to content itself. These strategies allow them to restrict information based on social knowledge, not structural access. While not all teenagers are carefully crafting content to be understood by a limited audience, many are exploring techniques to express themselves privately in situations where they assume that others are watching. They are not always prepared for how their content gets misinterpreted - and they still believe that they should have the right to be let alone - but they are actively creating counterpublics in full view.

\section{Privacy in Public}


Paper to be presented at Oxford Internet Institute's "A Decade in Internet Time: Symposium on the Dynamics of the Internet and Society" on September 22, 2011.

By using different strategies to achieve privacy in networked publics, teens are simultaneously revealing the importance of privacy and public life. They want to participate in networked publics, but they also want to have control over the social situations that take place there. They want to be visible, but only to certain people. They want to be recognized and validated, but only by certain people. This is not a contradictory stance; it parallels how people have always engaged in public spaces.

Examining the practices of urban life, sociologist Erving Goffman recognized that people regularly go out of their way to ignore each other in busy environments. In restaurants, people often dine close enough to overhear every conversation, but they pretend to not listen in. This act of "giving someone space" is a gift of privacy. Goffman calls it "civil inattention." 40 Civil inattention is a social norm, driven by an ideal of respect. Staring at someone or openly listening in on their conversations is a violation of social norms which makes people uneasy because it is experienced as an invasion of privacy. For teens, the same holds true online; they expect people most notably, those who hold power over them - to respect their space.

Teens often use the language of surveillance or monitoring to highlight the difference between people looking at them for sociable purposes rather than a power-laden gaze. For example, in Iowa, 17-year-old Sam explains: "I just think it's a complete invasion of your privacy to look at your kids' Facebook unless you really feel like they're in danger. But I know that there are parents that monitor their kids' Facebook." Sam recognizes that most parents engage in acts of surveillance because they are worried, but he still doesn't agree with this. In other words, just because people have access doesn't mean that they're welcome. This is a refrain that underscores teens' general attitudes towards privacy in networked publics.

Both online and offline, teens have been excluded from public spaces or told that they aren't welcome. As Gill Valentine has documented, moral panics - such as "stranger danger" - are often used to justify young people's exclusion from public places. ${ }^{41}$ In examining how public parks went from child-friendly to dangerous through the use of stranger danger messaging, she argued that "by reproducing a misleading message about the geography of danger, stranger-danger educational campaigns contribute towards producing public space as 'naturally' or 'normally' an adult space where children are at risk from 'deviant' others." ${ }^{2}$ These same moral panics have been used to explain why teens should not be using social network sites. ${ }^{43}$ Yet teens continue to flock to networked publics precisely because they are

40 Goffman, E. 1966. Behavior in public places: notes on the social organization of gatherings. New York: Simon and Schuster.

${ }^{41}$ Valentine, Gill. 2004. Public Space and the Culture of Childhood. Hants, UK: Ashgate.

42 Ibid, p. 27.

${ }^{43}$ Marwick, Alice. 2008. “To Catch a Predator? The MySpace Moral Panic.” First Monday 13(6): article

3. Retrieved December 3, 2008

(http://www.uic.edu/htbin.cgiwrap/bin/ojs/index.php/fm/article/view/2152/1966). 
some of the only spaces to which they have access. ${ }^{44}$ In trying to create a place for themselves in these spaces, they are not trying to be public, but rather, to be in a public. They want a space where they can socialize with peers and make sense of public life more generally.

Public life has value beyond political ideals; it is through participation in public life that people develop a sense of social norms, learn to navigate social relations, and begin to understand society writ large. The politicized public sphere cannot exist without the social public sphere. By engaging in networked publics, teens are taking the first step towards being public citizens; they are trying to understand who they are in relation to larger society. Engaging in public life does not entail throwing privacy out the window.

Privacy is in a state of flux not because the values surrounding it have radically changed, but because the infrastructure through which people engage with each other has. Networked technologies introduce new challenges, particularly in environments that are public-by-default. Privacy cannot be assumed, especially when powerful individuals or entities are interested in leveraging newfound opportunities for access to undermine social norms. When parents assert that they have the right to know simply because information is accessible, they undermine their children's agency. And agency is essential to being able to achieve privacy.

Fundamentally, privacy is a social norm. Legal regulation is legislated to protect individuals from harm. The market competes in opposite directions, trying to "win" both by enhancing privacy and leveraging opportunities to invade people's privacy for financial gains. Likewise, technologies will be built both to protect and erode privacy. But when it comes to social privacy, the biggest battles will be around the social norms that regulate it. In other words, what is socially appropriate in networked publics? How are norms signaled and violations recognized? What social sanctions can be used to curb violations? There are no clear answers to this, but what is clear is that teenagers are working hard to bring social norms into the equation. They're developing strategies for managing privacy in public spaces as they try to assert control over social situations. They may not always be successful, and they may consistently face violations of their privacy, but they are not discarding privacy as a result.

\section{References}

Allen, A. L. (1999). Coercing Privacy. William and Mary Law Review 40 (3): 723-724.

Anderson, Benedict. (2006). Imagined Communities: Reflections on the Origin and Spread of Nationalism. New ed. New York: Verso.

${ }^{44}$ boyd $2008 \mathrm{~b}$. 
Arendt, Hannah. (1998). The Human Condition. Chicago, IL: University of Chicago Press

boyd, danah (2006). "Friends, Friendsters, and MySpace Top 8: Writing Community Into Being on Social Network Sites." First Monday, 11 (12).

boyd, d. (2007). Why youth (heart) social network sites: The role of networked publics. In Youth, identity and digital media, ed. D. Buckingham, 119-142. Cambridge, MA: MIT Press.

boyd, d. (2008a). "Facebook's Privacy Trainwreck: Exposure, invasion, and social convergence." Convergence: The International Journal of Research into New Media Technologies 14 (1): 13-20.

boyd, d. (2008b). Taken out of context: American teen sociality in networked publics. PhD Dissertation, University of California, Berkeley.

http://papers.ssrn.com/sol3/papers.cfm?abstract_id=1344756.

boyd, danah and Eszter Hargittai (2010). "Facebook Privacy Settings: Who Cares?" First Monday 15 (8).

Brandimarte, L., Acquisti, A., and Loewenstein, G. (in review) "Privacy Concerns and Information Disclosure: An Illusion of Control Hypothesis."

Cohen, J. E. (2003). DRM and privacy. Communications of the ACM, 46, 46-49

Gavison, Ruth. (1980). Privacy and the limits of the law. Yale Law Journal 89: 421471.

Esguerra, R. (2009). Google CEO Eric Schmidt Dismisses the Importance of Privacy. Electronic Frontier Foundation. Retrieved from https://www.eff.org/deeplinks/2009/12/google-ceo-eric-schmidt-dismissesprivacy

Fraser, Nancy. (1992). "Rethinking the Public Sphere: A Contribution to the Critique of Actually Existing Democracy." Pp. 109-142 in Habermas and the Public Sphere, edited by Craig Calhoun. Cambridge, MA: The MIT Press. (page 123)

Goffman, E. (1966). Behavior in public places: notes on the social organization of gatherings. New York: Simon and Schuster.

Habermas, Jèurgen. 1991. The Structural Transformation of the Public Sphere: An Inquiry into a Category of Bourgeois Society. Cambridge, MA: MIT Press. 
Hoofnagle, Chris Jay, Jennifer King, Su Li, and Joseph Turow. (2010, April 14). “How Different are Young Adults from Older Adults When it Comes to Information Privacy Attitudes and Policies?" Working paper available at:

http://papers.ssrn.com/sol3/papers.cfm?abstract_id=1589864

Johnson, B. (2010, January 11). Privacy no longer a social norm, says Facebook founder. The Guardian. London. Retrieved from http://www.guardian.co.uk/technology/2010/jan/11/facebook-privacy.

Lamont, M., and V. Molnar. (2002). The study of boundaries in the social sciences. Annual Review of Sociology 167-196.

Lenhart, Amanda, K. Purcell, A. Smith, and K. Zickuhr. (2010). Social media and young adults. Washington, DC: Pew Internet \& American Life Project, February 3. http://pewinternet.org/Reports/2010/Social-Media-and-Young-Adults.aspx.

Lessig, Lawrence. (2006). Code: Version 2.0. New York: Basic Books. Retrieved from http://codev2.cc/

Livingstone, Sonia. (2005). Audiences and Publics: When Cultural Engagement Matters for the Public Sphere. Portland, OR: Intellect

Locke, John L. (2010). Eavesdropping: An Intimate History. New York: Oxford University Press, USA.

Marwick, Alice. (2008). To Catch a Predator? The MySpace Moral Panic. First Monday 13(6): article 3.

http://www.uic.edu/htbin.cgiwrap/bin/ojs/index.php/fm/article/view/2152/196 6.

Marwick, Alice, Murgia-Diaz, D., \& Palfrey, John. (2010). Youth, privacy and reputation (literature review) (Berkman Center Research Publication No. 2010-5). Boston: Berkman Center for Internet and Society at Harvard University. Retrieved from http://papers.ssrn.com/sol3/papers.cfm?abstract_id=1588163

Marwick, Alice and danah boyd. (2011b). "The Drama! Teens, Gossip and Celebrity." Popular Culture Association/American Culture Association Annual Meeting, San Antonio, TX, April 20-24.

Marwick, Alice and danah boyd. (2011a). "I tweet honestly, I tweet passionately: Twitter users, context collapse, and the imagined audience." New Media \& Society 13 (1): 114-133. 
Misur, S. (2011, April 11). Old Saybrook High School makes privacy point; Some perturbed when real students shown in social-media slide show. Shoreline Times. New Haven, CT. Retrieved from

http://www.shorelinetimes.com/articles/2011/04/11/news/doc4da2f3cb5caae51 8276953.txt

Nippert-Eng, Christena E. (2010). Islands of Privacy. Chicago: University of Chicago Press.

Nissenbaum, Helen. (2010). Privacy in Context: Technology, Policy, and the Integrity of Social Life. Palo Alto, CA: Stanford University Press.

Petitcolas, Fabian A. P., Ross J. Anderson, and Markus G. Kuhn. (1999, July).

"Information Hiding: A survey." Proceedings of the IEEE (special issue on protection of multimedia content) 87 (7): 1062-78.

Regan, P. (1995). Legislating Privacy. Chapel Hill: University of North Carolina Press

Reiman, J. (1976). Privacy, intimacy and personhood. Philosophy and Public Affairs 6(1): 26-44.

Solove, Daniel J. (2004). The digital person: Technology and privacy in the information age. New York: New York University Press

Solove, Daniel J. (2007). 'I've Got Nothing to Hide' and Other Misunderstandings of Privacy. San Diego Law Review 44: 762.

Strandburg, K. J. (2011). Home, Home on the Web: The Fourth Amendment and Technosocial Change. Maryland Law Review.

Valentine, Gill. (2004). Public Space and the Culture of Childhood. Hants, UK: Ashgate

Warner, Michael. 2002. Publics and Counterpublics. Cambridge, MA: MIT Press

Warren, S.D. \& Brandeis, L.D., (1890). Right to Privacy. Harvard Law Review, 4, 193.

Westin, A. (1967). Privacy and Freedom. New York: Atheneum.

Zimmer, Michael. (2007). The Quest for the Perfect Search Engine: Values, Technical Design, and the Flow of Personal Information in Spheres of Mobility (PhD Dissertation, Department of Media, Culture, and Communication). New York University, New York. 